\title{
Procesos electorales en Ecuador. 10 años de elecciones y estabilidad democrática (2006-2016)
}

\section{Electoral processes in Ecuador. 10 years of elections and democratic stability (2006-2016)}

Patricio Trujillo

Recepción: 10 de octubre de 2016 Aceptación: 08 de diciembre de 2016

\begin{abstract}
Resumen
La democracia liberal implementada en Ecuador fue cuestionada por la ciudadanía en las últimas dos décadas y, por ende, la legitimidad de sus instituciones. Los partidos políticos ingresaron en una sostenida etapa de desgaste, como consecuencia de continuos errores políticos que evidenciaron una pérdida en su representación. Los ciudadanos obtuvieron mayores respuestas a sus demandas políticas a través de movimientos u organizaciones de la sociedad civil antes que de los partidos políticos o del propio Estado. Entre 1996 y 2006 fue en este panorama que se desenvolvió la partidocracia ecuatoriana representada por líderes populistas de muy baja credibilidad, los mismos que se evidencian como inestables y muy poco sostenibles en el tiempo. La política y los políticos estaban devaluados, con un alto descrédito y poca popularidad, fue una etapa histórica que evidenció el hastío por la política. El neoliberalismo cumplía con uno de sus princiales objetivos, la despolitización de una gran parte de la población, disminuyendo las instituciones del Estado y anulando los partidos políticos. En esta compleja etapa de crisis es donde aparece la denominada Revolución Ciudadana y el Movimiento PAIS, convertidos en estos útimos 10 años en el proyecto político más importante del Ecuador contemporáneo.

Palabras claves: democracia, elecciones, revolución ciudadana, movimientos, partidos.
\end{abstract}




\begin{abstract}
The Liberal democracy implemented in Ecuador was questioned in the past two decades and hence the legitimacy of its institutions and political parties. Consequently, their representation was less and the citizens did not get answers to their demands from political movements or civil society organizations rather than politicians or parties in the State itself. It was in this scenario that the Ecuadorian parties appeared represented by populist leaders with very low credibility. Politics and politicians were devalued, with high disgrace and unpopularity. It was a historic time that showed the aversion for politics. Neoliberalism met one of its main objectives, the depoliticization of a large portion of the population, reducing State institutions and nullifying political parties. In this complex crisis stage the so-called Citizen Revolution and the PAIS movement become these last years the most important and contemporary political project in contemporary Ecuador.
\end{abstract}

Keywords: democracy, elections, citizen revolution, movements, parties. 


\section{Introducción: El Ecuador ingobernable}

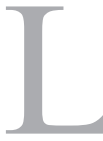

a historia política del Ecuador entre el periodo de 1996 a 2006, se caracterizó por inestabilidad, desconfianza y continuas revueltas populares que lograron cambiar, en este lapso de 10 años, a tres presidentes constitucionales (Abdalá Buracam, Jamil Mahuad, Lucio Gutiérrez), a través de varios mecanismos como: resoluciones del Congreso, golpes militares o levantamientos populares, creando una alta des-institucionalización y des-legitimación tanto en los partidos como a los líderes políticos (Ramírez, 2010).

Según Carlos de la Torre (2012) esta etapa histórica se relaciona a gobiernos de corte populistas muy inestables. El gobierno de Bucaram, por ejemplo, no pudo desarrollar ningún tipo de política relevante en ningún orden del Estado, duró únicamente seis meses. Bucaram, Alarcón, Mahuad, junto a varios miembros de sus gobiernos, fueron acusados de corrupción, lo que ocasionó protestas sociales, siendo el pretexto para que las élites oligárquicas organicen, gestionen y comanden sus respectivas salidas, renuncias o golpes de Estado. Los políticos fueron imaginados como corruptos, mentirosos y representantes de intereses corporativos de grupos económicos ligados a la banca. La política y los políticos estaban devaluados, con un alto descrédito y poca popularidad. Fueron diez años de continuas crisis políticas como consecuencia de una agresiva crisis económica que provocó un alejamiento de la sociedad hacia la política.

Un alto porcentaje de la población del Ecuador, en especial jóvenes, evidenció un hastío por la política. Coincidencialmente la propuesta neoliberal cumplía con uno de sus principales objetivos: despolitizarlos. La participación política fue devaluada, mucho más importante fue involucrarse en campos económicos empresariales ${ }^{1}$, dejando un vacío en el campo de la

1 Era mucho más importante ser gerente de una empresa y acumular capital que ingresar al campo político al que se lo imaginaba como corrupto. 
representación política vía procesos electorales. Este vaciamiento contribuyó a que la calidad de los políticos y de la política estuviera en el entredicho, contribuyendo a una sistemática des-institucionalización de los partidos políticos (Alcántara, 2011). Las instituciones del Estado fueron debilitadas con la finalidad de reemplazarlas por empresas privadas y organizaciones no gubernamentales (ONG), quienes pretendieron manejar el destino de las poblaciones, incluido sus decisiones políticas. Para Slavoj Zizek (1998: 13), el neoliberalismo, en su afán de liberar al capitalismo de todas las ataduras posibles, negó la política, deslegitimó al Estado y despolitizó a la sociedad a través de una ideología que negó a la ideología, presentándose como aséptica y no contaminada. El Ecuador no escapó de esa realidad histórica y luego de más de tres décadas de promesas incumplidas, del desmejoramiento sistemático de la calidad de vida, de la implementación de leyes y recetas económicas que ponían al mercado por encima de las poblaciones más vulnerables, el proyecto neoliberal fue perdiendo poco a poco legitimidad ante un contexto de desigualdad, injusticia y pobreza.

En esa misma etapa (1996-2006), curiosamente la mayoría de los medios de información colectiva se fortalecieron como empresas privadas vinculadas a grupos de poder económico cercanos a banqueros, consolidando una versión de la prensa a la que autodenominaron como "independiente" pero muy vinculada a grupos monopólicos oligárquicos. Como complemento a esta imagen de nación, ni los movimientos sociales (obreros, sindicales, étnicos), ni los partidos políticos tradicionales, encontraron vías para consolidarse como representantes de la población; quizá unicamente el movimiento indígena fue representativo, puesto que logró dar un salto político, transformando eficientemente su discurso de reconocimiento cultural hacia una propuesta que lo consolidaba como un actor político alternativo, imaginado como referente de la lucha popular (Ramírez, 2011). Ante el descrédito de los partidos tradicionales, el movimiento indígena y otros actores, en especial movimientos sociales y políticos, aparecen compitiendo 
los espacios de representación política y cuestionando a la denominada partidocracia, dentro de un complejo modelo de Estado de corte más postneoliberal (Arenas, 2012).

Fue en esos complejos contextos de inestabilidad y poca credibilidad de la política y de los políticos donde aparece la Revolución Ciudadana y el movimiento PAIS $^{2}$, como proyecto político-electoral que se consolidó alrededor de la figura carismática de Rafael Correa, un académico poco conocido en el ambiente político tradicional. Correa logró posicionar un pacto político, que le permitió cohesionar heterogéneas tendencias ciudadanas alrededor del movimiento PAIS y legitimar un discurso contra un anterior modelo de gobierno neoliberal. En el neoliberalismo, la representación política fue reducida para un gran porcentaje de ciudadanos, quienes en cambio encontraron mayores posibilidades de respuestas a sus demandas a través de organizaciones de la sociedad civil, antes que de los partidos políticos o en el propio Estado (Ramírez, 2011). Correa, utilizando un discurso antineoliberal, planteó un plan de gobierno de corte ciudadano, que pretendió cambiar el imaginario negativo de la política hacia la construcción de una nueva sociedad denominada como del "Buen Vivir" (Larrea, 2011), seduciendo a una amplia población de clase media urbana, que se convirtió en su base electoral.

\section{Los procesos electorales como campos de legitimidad política}

Este ensayo analiza la importancia de los procesos electorales, de triunfos en elecciones y su relación con el fortalecimiento de la democracia y la legitimidad política. Toma como estudio de caso al Ecuador, puesto se presenta como un fenómeno político graficante para el análisis político, sobre todo en la última década.

2 Movimiento Patria Altiva i Soberana (PAIS). 
Luego del ingreso a la democracia en 1979, los gobiernos de turno tuvieron estabilidad, a pesar de enfrentar profundas crisis económicas, terminaron sus mandatos, fue el caso de Roldós y Hurtado (1979-1984) ${ }^{3}$, Febres-Cordero (1984-1988), Borja (1988-1992) y Durán-Ballén (19921996). Los procesos electorales para la elección de Presidente, tuvieron como característica segundas vueltas. Las elecciones se convertían en los rituales donde los partidos políticos y sus representantes se consolidaban como legítimos o no frente a la ciudadanía.

\section{Tabla 1.}

Porcentajes obtenidos para candidatos presidenciales (1979-2002)

\begin{tabular}{|c|c|c|c|c|c|c|c|c|}
\hline \multirow[t]{2}{*}{ Año } & \multirow[t]{2}{*}{ Candidato } & \multirow[t]{2}{*}{ Partido } & \multicolumn{3}{|c|}{ Primera Vuelta } & \multicolumn{3}{|c|}{ Segunda Vuelta } \\
\hline & & & Votos & $\%$ & $\begin{array}{l}\text { Varia- } \\
\text { ción }\end{array}$ & Votos & $\%$ & $\begin{array}{l}\text { Varia- } \\
\text { ción }\end{array}$ \\
\hline \multirow[b]{2}{*}{1979} & Jaime Roldós & $\mathrm{CFP}$ & 381,215 & 27,7 & \multirow[b]{2}{*}{3,64} & $1,025,148$ & 68,49 & \multirow[b]{2}{*}{36,98} \\
\hline & $\begin{array}{l}\text { Sixto Durán } \\
\text { Ballén }\end{array}$ & PSC & 328,461 & 23,86 & & 471,657 & 31,51 & \\
\hline \multirow{2}{*}{1984} & $\begin{array}{c}\text { León } \\
\text { Febres-Cordero }\end{array}$ & PSC & 600,563 & 27,2 & \multirow{2}{*}{1,53} & $1,381,709$ & 51,54 & \multirow{2}{*}{3,08} \\
\hline & Rodrigo Borja & ID & 634,327 & 28,73 & & $1,299,089$ & 48,46 & \\
\hline \multirow[b]{2}{*}{1988} & Rodrigo Borja & ID & 744,409 & 24,48 & \multirow[b]{2}{*}{6,87} & $1,699,895$ & 54 & \multirow[b]{2}{*}{8,00} \\
\hline & Abdalá Bucaram & PRE & 553,482 & 17,61 & & $1,448,059$ & 46 & \\
\hline \multirow{2}{*}{1992} & $\begin{array}{l}\text { Sixto Durán- } \\
\text { Ballén }\end{array}$ & PUR & $1,089,154$ & 31,88 & \multirow{2}{*}{6,85} & $2,146,762$ & 57,32 & \multirow{2}{*}{14,64} \\
\hline & Jaime Nebot & PSC & 855,234 & 25,03 & & $1,598,707$ & 42,68 & \\
\hline \multirow{2}{*}{1996} & Abdalá Bucaram & PRE & $1,001,071$ & 26,28 & \multirow[t]{2}{*}{0,89} & $2,285,397$ & 54,47 & \multirow[t]{2}{*}{8,94} \\
\hline & Jaime Nebot & PSC & $1,036,101$ & 27,17 & & $1,910,651$ & 45,53 & \\
\hline
\end{tabular}

3 Jaime Roldós fue el primer presidente electo en la nueva etapa democrática (1979), sin embargo, no termina su periodo constitucional ya que muere en un accidente de avión en 1981, le sucede su vicepresidente Osvaldo Hurtado. 


\begin{tabular}{|c|c|c|c|c|c|c|c|c|}
\hline \multirow[t]{2}{*}{1998} & Jamil Mahuad & DP & $1,342,114$ & 34,91 & \multirow[t]{2}{*}{8,31} & $2,243,000$ & 51,16 & \multirow[t]{2}{*}{2,33} \\
\hline & Álvaro Noboa & PRE & $1,022,887$ & 26,6 & & $2,140,481$ & 48,83 & \\
\hline \multirow[t]{2}{*}{2002} & Lucio Gutiérrez & $\begin{array}{c}\text { PSP, } \\
\text { MPD, } \\
\text { MUPP/ } \\
\text { NP }\end{array}$ & 913,113 & 20,43 & \multirow[t]{2}{*}{3,06} & $2,726,476$ & 54,38 & \multirow[t]{2}{*}{8,76} \\
\hline & Álvaro Noboa & PRIAN & 776,132 & 17,37 & & $2,286,819$ & 45,62 & \\
\hline
\end{tabular}

Fuente: Consejo Nacional Electoral, 2014.

Elaborado por: Autor.

Un segundo periodo democrático se consolida entre 2006 y 2014, luego de una inestable etapa que finaliza con el derrocamiento de Lucio Gutiérrez, elegido en 2002, pero quien no termina su mandato y es Alfredo Palacio, su vicepresidente, quien prepara el camino para la sucesión y elección de nuevas autoridades. Entre 2006 y 2014 se llevaron a cabo 10 procesos electorales, entre consultas populares (2), referéndum (1), elecciones para Presidente (2), Asambleístas (2) y de gobiernos seccionales (3) (Trujillo, 2016). Los continuos procesos electorales contribuyeron a fortalecer la democracia y a generar estabilidad y legitimidad política, algo anhelado por la sociedad ecuatoriana, cansada de etapas anteriores de evidente inestabilidad e ilegitimidad de los partidos y los políticos. La legitimidad del sistema democrático se iba consolidado en los procesos electorales y en los resultados cada vez más positivos, que fortalecían a un movimiento político que se distanciaba de los partidos tradicionales, quienes en cambio ingresaban en una etapa de desaparición.

\section{La elección para consulta a Asamblea Constituyente 2007}

La consulta popular (SÍ o NO) para la conformación de una Asamblea Constituyente que elabore una nueva Constitución, tuvo lugar el 15 de abril de 2007 y en ella el Sí obtuvo el 81.72 por ciento de los votos válidos. Este 
proceso electoral fue posible, gracias a una exitosa operación política por parte del gobierno de la Revolución Ciudadana a la que se denominó el "Congreso de los manteles", designación mediática que dio la prensa local a esta maniobra política, donde se logró la destitución de 56 diputados electos en las elecciones del 2006 (Montúfar, 2012).

Al destituirlos, se conformó una nueva mayoría en el Congreso, afín al gobierno de Rafael Correa. Con esto, se logró la aprobación por parte del Congreso para la convocatoria a una consulta popular, y así cumplir con la principal oferta de campaña: una Asamblea Constituyente, que cambiaría la Constitución Política de Ecuador. Para Montúfar (2012:13), el movimiento PAIS y sus principales aliados hasta ese momento: Movimiento Popular Democrático (MPD), Unión Nacional de Educadores (UNE), Movimiento Plurinacional PACHAKUTIK, Confederación de Nacionalidades Indígenas del Ecuador (CONAIE), Frente Unitario de Trabajadores (FUT), así como movimientos políticos más locales, tales como Ruptura de los 25, Concertación, Acción Regional por la Equidad (ARE), Movimiento de Izquierda Revolucionaria (MIR) y otros de alcance más nacional como: Izquierda Democrática (ID), Partido Roldosista Ecuatoriano (PRE) y Partido Socialista, formaron una mayoría en el Congreso Nacional, apoyando la convocatoría a una consulta popular que legitimara la instalación de la Asamblea Constituyente.

El panorama político fue halagador para la Revolución Ciudadana y el movimiento PAIS, puesto que los resultados electorales de la consulta popular realizada en 2007 fueron superiores frente a la votación obtenida por sus rivales políticos, agrupados alrededor de partidos tradicionales, en especial su principal opositor, el Partido Social Cristiano. El Sí por la instalación de una Asamblea que redactase una nueva Constitución, triunfó configurando un nuevo mapa electoral en el Ecuador, posicionando un nuevo y gravitante actor político: la Revolución Ciudadana. Luego del triunfo electoral para la 
aprobación de la consulta para la Asamblea Constituyente, Rafael Correa se consolidó como el líder indiscutible de la Revolución Ciudadana y del movimiento PAIS.

La elección para designación de Asambleistas Constituyentes, 2007

Las elecciones realizadas el 30 de septiembre de 2007 para elegir Asambleístas constituyentes pusieron de manifiesto la debilidad de los partidos tradicionales, quienes en décadas anteriores habían gobernado. Los partidos que sobrevivieron fueron el Partido Sociedad Patriótica (PSP) del ex Presidente Lucio Gutiérrez y el Partido Renovación Institucional Alianza Nacional (PRIAN) de Álvaro Noboa, un empresario del sector bananero. Los dos partidos y sus líderes se presentaron como una alternativa al espacio dejado por los desprestigiados partidos tradicionales. Sin embargo, en la elección del 30 de septiembre de 2007 lograron un reducido número de asambleístas constituyentes. Esto contrastó con la fuerza electoral del movimiento Alianza PAIS, que obtuvo 80 de 130 asambleístas constituyentes, logrando así una mayoría absoluta que consolidó su legitimidad política (Muñoz, 2009). 


\section{Gráfico 1.}

Resultados de elecciones para la Asamblea Constituyente, 2007

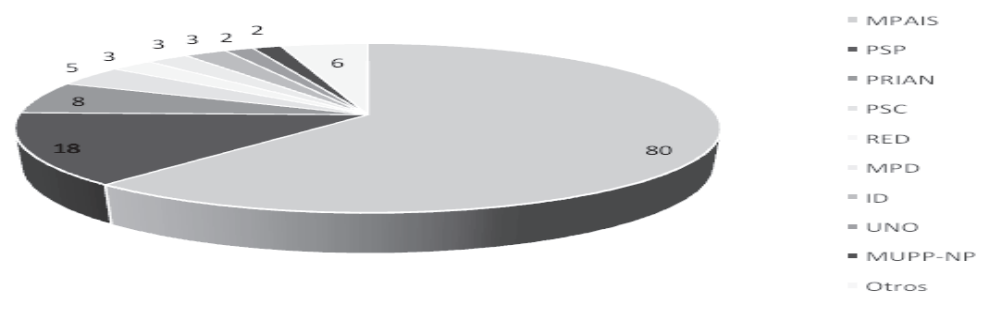

Fuente: CNE, 2011.

Elaborado por: Autor.

La oposición política fragmentada ganó 50 puestos, permanenciendo como una minoría que agrupaba a heterogéneos líderes de partidos políticos tradicionales y movimientos ciudadanos cohesionados por un discurso contrario a las reformas constitucionales y al movimiento PAIS.

La elección para consulta popular y referéndum, 2011

Pocos meses luego del 30-S $\mathrm{S}^{4}$, en enero del 2011, Rafael Correa decide

4 El 30 de septiembre del 2010, el presidente Constitucional de la República del Ecuador Rafael Correa, fue obligado a permanecer en las instalaciones del Regimiento de Policía, Quito Núm.1, manteniéndolo aislado con un pequeño grupo de seguridad y miembros de su gabinete, sin poder salir por varias horas. En la noche, grupos combinados de élite del ejército ecuatoriano y de la policía iniciaron el rescate que terminó con su liberación, pero el enfrentamiento armado provocó la muerte de civiles y militares (Ramos y Páez, 2010). 
convocar a una consulta popular y referéndum para reformar la Constitución, elección que mediría la aceptación, legitimidad y respaldo popular del Presidente, la Revolución Ciudadana y el movimiento PAIS como proyecto electoral con alcance nacional.

El escenario político para el movimiento PAIS en 2011 se presentó complicado. Por un lado, fue la primera vez en su historia política que participaba en unas elecciones dividido y sin el apoyo mayoritario al que estaba acostumbrado. Por otro, el movimiento PAIS enfrentaba a una oposición mucho más cohesionada, alrededor de una campaña común por el NO al gobierno y NO a la consulta popular. Cabe anotar, además, que el tipo de proceso electoral (consulta y referéndum) y sobre todo las preguntas consultadas no generaron mayor interés en la población. Las preguntas controversiales fueron las relacionadas al referéndum, puesto que pretendían una reforma constitucional y legal ${ }^{5}$, estas fueron las que la oposición enfrentó con mayor coordinación (Montúfar, 2012). Ospina (2011:7), en cambio, considera que las preguntas controversiales fueron las relacionadas con el poder judicial y la forma en la que se pretendía la selección de los magistrados de la nueva Corte de Justicia: "la forma de designación de las más altas autoridades de la justicia, retirándolas de manos del llamado "quinto poder", el Consejo de Participación Ciudadana y Control Social (CPCCS)".

Una vez aprobadas las preguntas, tanto por la Corte Constitucional, como posteriormente por el Consejo Nacional Electoral (CNE), la campaña inició en mayo del 2011, tanto para el gobierno como para la oposición. Los resultados obtenidos en la consulta popular y referéndum no fueron los esperados para el movimiento PAIS. A pesar del triunfo general a nivel nacional por el SÍ, un corto margen entre el SÍ y el NO, agrupó a una

5 Se refieren a la forma de combatir la inseguridad. El presidente propone modificar las garantías constitucionales del plazo de la prisión preventiva para evitar que los sospechosos puedan ser liberados antes de su sentencia el plazo en la Constitución de 2008, como en la de 1998, es de un año (Ospina, 2011). 
oposición ${ }^{6}$ que veía en los resultados tan apretados, un triunfo político. El NO, además, había ganado en muchas provincias de las regiones Sierra y Amazonía, donde, por primera vez, se cohesionaba una oposición política frente al gobierno ${ }^{7}$. Sin embargo, los resultados revelaban otro fenómeno, el nuevo respaldo popular del movimiento PAIS se localizaba en regiones de la Costa.

Tabla 2.

Resultados Consulta Popular 2011 a nivel nacional

\begin{tabular}{ccccc}
\hline PROVINCIA & SÍ & NO & BLANCO & NULO \\
\hline CARCHI & 40,74 & 50,06 & 4,55 & 5,18 \\
IMBABURA & 47,37 & 41,29 & 6,32 & 5,69 \\
PICHINCHA & 48,44 & 45,03 & 2,29 & 3,91 \\
STO DOMINGO & 51,37 & 37,63 & 5,74 & 5,25 \\
COTOPAXI & 34,31 & 52,73 & 7,12 & 5,98 \\
TUNGURAHUA & 35,63 & 53,93 & 4,56 & 5,32 \\
BOLIVAR & 29,34 & 53,45 & 11,52 & 7,78 \\
CHIMBORAZO & 35,97 & 48,1 & 10,81 & 6,51 \\
CAÑAR & 42,77 & 44,08 & 8,9 & 5,94 \\
AZUAY & 53,68 & 36,19 & 5,65 & 5,02 \\
LOJA & 42,3 & 47,95 & 6,67 & 3,78 \\
ESMERALDAS & 46,48 & 37,57 & 8,72 & 6,31 \\
MANABI & 50,47 & 33,84 & 9 & 6,1 \\
SANTA ELENA & 51,87 & 33,78 & 9,86 & 5,09 \\
LOS RIOS & 49,75 & 34,38 & 8,91 & 6,61
\end{tabular}

6 Reunida en los siguientes sectores: Partido Social Cristiano (PSC), Partido Sociedad Patriotica (PSC), Pachakutik-CONAIE, MPD-UNE, Ruptura de los 25, Montecristi Vive.

7 https://goo.gl/RDHyoJ (Consultado, enero 2014). 


\begin{tabular}{ccccc} 
GUAYAS & 49,24 & 39,65 & 5,18 & 5,43 \\
EL ORO & 54,52 & 35,78 & 4,92 & 4,98 \\
SUCUMBIOS & 45,34 & 41,87 & 6,63 & 6,29 \\
NAPO & 34,54 & 55,82 & 6,64 & 4,23 \\
ORELLANA & 38,95 & 49,07 & 7,96 & 5,09 \\
PASTAZA & 34,27 & 55,48 & 6,51 & 4,98 \\
MORONA & 28,34 & 61,73 & 6,37 & 4,86 \\
ZAMORA & 34,57 & 55,25 & 7,14 & 4,35 \\
GALÁPAGOS & 48,04 & 43,81 & 3,82 & 5,09 \\
\hline
\end{tabular}

Fuente: CNE, 2012.

Elaborado por: Autor.

A nivel regional, los resultados obtenidos en la consulta advertían que, a pesar de ganar en todas las preguntas ${ }^{8}$, los porcentajes de la votación decrecían comparados con procesos anteriores, en especial en las denominadas regiones sensibles (Unda, 2011), con alta población rural, pobre e indígena, como Sierra Centro, donde el NO a las reformas ganó en las 4 provincias, y en Amazonía, donde el NO ganó en 5 de 6 provincias.

En las provincias de la Sierra Centro fue donde la disminución en votación para el movimiento PAIS en 2011 se tornó dramática, en especial si se las comparaba con los dos procesos electorales de consultas populares anteriores, así:

$8 \mathrm{https} / / /$ goo.gl/RbFy6Z (Consultado, enero 2015). 


\section{Tabla 3.}

Histórico de votación consultas populares para movimiento PAIS, en Sierra Centro (2007-2011)

\begin{tabular}{cccc}
\hline PROVINCIA & $\mathbf{2 0 0 7}$ & $\mathbf{2 0 0 8}$ & $\mathbf{2 0 1 1}$ \\
\hline COTOPAXI & $84,65 \%$ & $65,16 \%$ & $34,31 \%$ \\
TUNGURAHUA & $85,46 \%$ & $57,87 \%$ & $35,63 \%$ \\
CHIMBORAZO & $80,98 \%$ & $62,17 \%$ & $35,97 \%$ \\
BOLÍVAR & $80,74 \%$ & $53,21 \%$ & $29,34 \%$ \\
\hline
\end{tabular}

Fuente: CNE, 2012.

Elaborado por: Autor.

En la Sierra Centro, el triunfo del NO se localizó en zonas urbanas y de clase media. Ciudades como: Ambato, Riobamba, Guaranda, Latacunga, se convertían en los espacios de la oposición contra el gobierno de Correa y su maquinaria política (Ospina, 2011; Unda, 2011).

\section{Tabla 4.}

Resultado de votación consulta 2011. Principales cantones urbanos Sierra Centro

\begin{tabular}{cccccc}
\hline PROVINCIA & CANTÓN & SI & NO & BLANCOS & NULOS \\
\hline COTOPAXI & LATACUNGA & $33,70 \%$ & $55,70 \%$ & $5,20 \%$ & $5,40 \%$ \\
TUNGURAHUA & AMBATO & $34,10 \%$ & $52,40 \%$ & $7,50 \%$ & $6,00 \%$ \\
CHIMBORAZO & RIOBAMBA & $37,50 \%$ & $51,30 \%$ & $6,00 \%$ & $5,30 \%$ \\
BOLIVAR & GUARANDA & $29,00 \%$ & $51,70 \%$ & $12,10 \%$ & $7,30 \%$ \\
\hline
\end{tabular}

Fuente: CNE, 2012.

Elaborado por: Autor. 
Por otro lado, en las provincias amazónicas como: Morona Santiago, Zamora, Napo, Orellana y Pastaza, los resultados a favor del NO fueron mayores en las poblaciones tanto rurales como en las urbanas. El SÍ ganó únicamente en una provincia amazónica: Sucumbíos.

\section{Tabla 5.}

Resultado de votación consulta 2011. Principales cantones urbanos Amazonia

\begin{tabular}{cccccc}
\hline PROVINCIA & CANTÓN & SI & NO & BLANCOS & NULOS \\
\hline NAPO & TENA & $30,80 \%$ & $60,20 \%$ & $5,50 \%$ & $3,40 \%$ \\
PASTAZA & PASTAZA & $34,30 \%$ & $55,60 \%$ & $5,60 \%$ & $4,50 \%$ \\
MORONA & & & & & \\
SANTIAGO & MORONA & $30,60 \%$ & $60,50 \%$ & $4,40 \%$ & $4,50 \%$ \\
SUCUMBIOS & AGRIO & $46,80 \%$ & $40,20 \%$ & $6,80 \%$ & $6,20 \%$ \\
ORELLANA & ORELLANA & $38,50 \%$ & $50,00 \%$ & $6,70 \%$ & $4,90 \%$ \\
ZAMORA & & & & & \\
CHINCHIPE & ZAMORA & $34,60 \%$ & $57,90 \%$ & $3,80 \%$ & $3,70 \%$ \\
\hline
\end{tabular}

Fuente: CNE, 2012.

Elaborado por: Autor.

Los resultados de la consulta popular de 2011, revelaron datos interesantes. 1) la estrategia política de la oposición fue mucho más eficiente, sobre todo en espacios territoriales, logrando un triunfo electoral no programado para el gobierno; 2) los estrategas del gobierno no lograron descifrar las relaciones políticas locales a pesar de una alta inversión pública; y, 3) el triunfo del NO en zonas urbanas y en regiones pobres y de alta exclusión social, como Sierra Centro y Amazonía, consolidó a la oposición (Trujillo, 2016). 


\section{Gráfico 2.}

Resultado elecciones 2007-2011 para movimiento PAIS

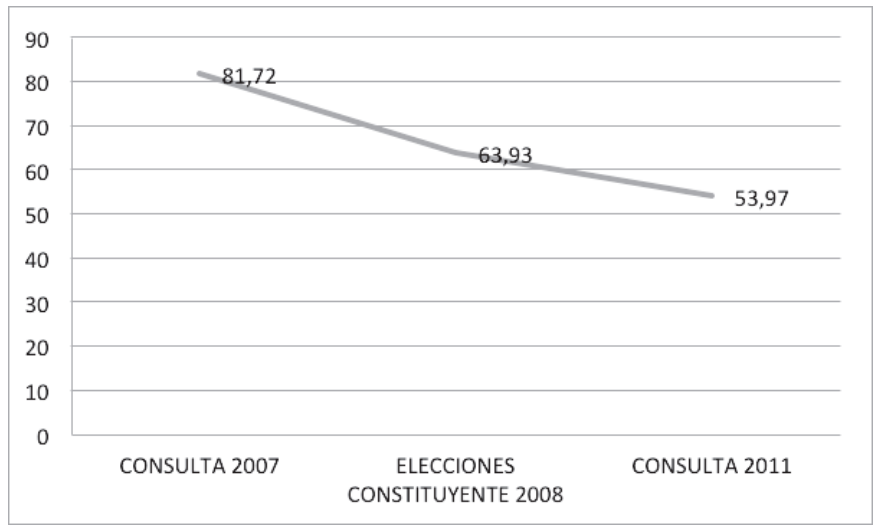

Fuente: CNE, 2012.

Elaborado por: Autor.

Como se observa en el gráfico anterior, la consulta popular del 2011 fue donde el movimiento PAIS obtuvo la menor cantidad de votos. Perdió casi 10 puntos porcentuales comparado con el referendum del 2008, y más de 27 puntos, comparándola con la consulta del 2007.

\section{Elecciones presidenciales y hegemonía política de la Revolución Ciudadana}

El 15 de octubre del 2006, Rafael Correa participó en su primera elección presidencial, donde compitieron 13 candidaturas que cubrían un amplio marco ideológico, político y regional. En la primera vuelta triunfó el empresario 
bananero y líder del PRIAN, Álvaro Noboa, con el 26,83\% de los votos. Correa logró un segundo lugar, representando al denominado movimiento ALIANZA PAIS (Patria Altiva I Soberana) obteniendo un 22,84\%, a pesar de su figura poco conocida como político a nivel nacional. Ambos compitieron en la segunda vuelta, realizada el 26 de noviembre, en la que Correa fue electo con el 56,67\% de los votos, luego de una intensa campaña y de haber moderado su discurso mediático al mostrarse como un ciudadano más de clase media, reiterar su compromiso con la dolarización e incluir a su familia en la campaña, dando cuenta de su devoción como católico practicante (Freidenberg, 2012). En su primera elección, Rafael Correa ganó la presidencia de la República con un discurso anti partidos políticos, siendo la primera vez, en la historia política del Ecuador, que un candidato presidencial triunfó sin listas de diputados y por lo tanto sin representantes ante el Congreso, fue un candidato sin partido (Ramírez, 2011). En su segunda participación (2009), luego de la Constituyente, Correa logró un triunfo en primera vuelta.

\section{Tabla 6.}

Histórico de votación elección presidente (2006-2013)

\begin{tabular}{|c|c|c|c|c|c|c|c|c|}
\hline \multirow[t]{2}{*}{ Año } & \multirow[t]{2}{*}{ Candidatos } & \multirow[t]{2}{*}{ Partido } & \multicolumn{3}{|c|}{ Primera Vuelta } & \multicolumn{3}{|c|}{ Segunda Vuelta } \\
\hline & & & Votos & $\%$ & $\begin{array}{l}\text { Varia- } \\
\text { ción }\end{array}$ & Votos & $\%$ & $\begin{array}{l}\text { Varia } \\
\text { ción }\end{array}$ \\
\hline \multirow{2}{*}{2006} & Rafael & $\begin{array}{c}\text { ALIANZA } \\
\text { PAIIS/PS- } \\
\text { FA }\end{array}$ & $1,246,333$ & 22,84 & \multirow{2}{*}{3,99} & $3,517,635$ & 56,67 & \multirow[t]{6}{*}{13,34} \\
\hline & $\begin{array}{l}\text { Alvaro } \\
\text { Noboa }\end{array}$ & PRIAN & $1,464,251$ & 26,83 & & $2,689,418$ & 43,33 & \\
\hline \multirow{2}{*}{2009} & $\begin{array}{l}\text { Rafael } \\
\text { Correa }\end{array}$ & $\begin{array}{l}\text { ALIANZA } \\
\text { PAÍS }\end{array}$ & $3,586,439$ & 51,99 & \multirow{2}{*}{$23,75 \%$} & & & \\
\hline & $\begin{array}{l}\text { Lucio Guti- } \\
\text { érrez }\end{array}$ & PSP & $1,947,830$ & 28,24 & & & & \\
\hline \multirow{2}{*}{2013} & $\begin{array}{l}\text { Rafael } \\
\text { Correa }\end{array}$ & $\begin{array}{l}\text { ALIANZA } \\
\text { PAÍS }\end{array}$ & 4.918 .000 & $57.14 \%$ & \multirow{2}{*}{$34.45 \%$} & & & \\
\hline & $\begin{array}{c}\text { Guillermo } \\
\text { Lasso }\end{array}$ & CREO & 1.946 .438 & $22.69 \%$ & & & & \\
\hline
\end{tabular}

Fuente: CNE, 2013.

Elaborado por: Autor. 
A continuación, el triunfo electoral del 2013, fue el más significativo, puesto que rompió, de-constituyó y re-significó varios “clivajes", que en el Ecuador antes de esa elección eran imaginados como inamovibles, tanto para el análisis político, como para las estrategias electorales ${ }^{10}$ (Freidenberg, 2012; Pachano, 2007; Polga, 2013).

[...]Clivajes son líneas de ruptura, existen cuatro líneas de división críticas o clivajes (clase, religión, etnia y cultura) para las sociedades contemporáneas. Para que una división estructural se transforme en clivaje, es necesario que dicha división sea profunda y visible por los individuos, es decir que sea sentida por los actores. De esta manera la división cumple su misión de configurar los lineamientos entre dos grupos o campos opuestos que se han institucionalizado con el tiempo. El clivaje constituye entonces una división observable que se transforma en la toma de conciencia de los actores de que ellos mismos se encuentran dentro y son parte del conflicto (Lipset y Rokkan, 2001:245-246).

En el caso ecuatoriano, se creía fundamental: a) mantener un denominado "balance regional" (Presidente Costa, Vicepresidente Sierra o viceversa), b) la necesidad de alianzas políticas con dirigentes de la Confederación de Nacionalidades Indígenas del Ecuador (CONAIE), c) alianzas con partidos y movimientos políticos tradicionales en territorio (Polga, 2013). El movimiento PAIS, con dos candidatos de la región Costa, sin alianzas nacionales con dirigentes indígenas ${ }^{11}$, y menos aún con la participación de líderes de partidos tradicionales, ganó la elección presidencial en primera vuelta y consiguió un triunfo histórico en 23 de las 24 provincias, obteniendo

9 “Tomando los orígenes históricos de los partidos políticos se los tipifica según tres líneas divisorias: nacionalismo versus separatismo, confesional versus laico, urbano versus agrario" (Lipset y Rokkan, 2001:245-246).

10 Potenciales alianzas, selección de candidatos, estrategias para las elecciones.

11 Existieron alianzas regionales como el caso del Prefecto Mariano Curicamac, en la provincia de Chimborazo en la sierra centro de Ecuador, región de alto porcentaje de población autoidentificada como indígena (Ramírez y Pagliorone, 2014). 
una mayoría absoluta de Asambleístas (100) con representación en todas las 24 provincias. Rafael Correa obtuvo una votación de 4.918 .482 (57.17\%), frente a su inmediato seguidor, el candidato Guillermo Lasso que obtuvo una votación de 1.951 .202 (22.68\%), y Alberto Acosta el candidato auto identificado como de la "verdadera izquierda" y con el apoyo de ciertos dirigentes indígenas, obtuvo 280.539 votos (3.26\%) a nivel nacional ${ }^{12}$.

\section{Gráfico 3.}

Histórico votación Rafael Correa (2006-2013)

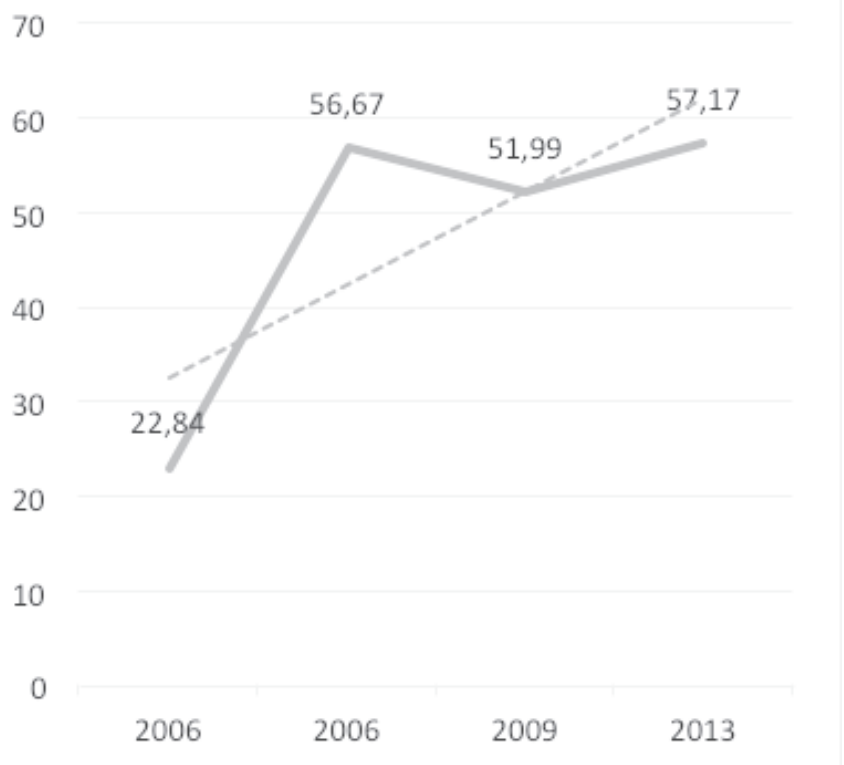

Fuente: CNE, 2011, 2013.

\section{Elaborado por: Autor.}

12 www.cne.gob.ec 
El triunfo del 2013 consolidó un proyecto político que por primera vez en la historia electoral del Ecuador tenía un alcance nacional, regional y local (Polga, 2013). Evidenciando también que potenciales alianzas políticas con ciertos dirigentes indígenas no alterarían el escenario electoral, puesto que la población indígena a la que representan es una minoría en el mapa étnico y electoral del Ecuador (7,3\%), y por lo tanto, no existe un peso decisivo en la votación a nivel nacional ${ }^{13}$. La amplia ventaja de Correa frente a sus opositores consolidó un triunfo inobjetable, deslegitimando cualquier duda de la oposición sobre la popularidad y aparente hegemonía a nivel nacional del proyecto político de la Revolución Ciudadana (Trujillo, 2013).

\section{Conclusiones: elecciones y hegemonía política}

Los procesos electorales han sido el campo ${ }^{14}$ donde la Revolución Ciudadana consolidó su propuesta política de cambio social, de la mano de Rafael Correa, un candidato jóven y de alto carisma, que, junto a su movimiento, propuso un pacto social, el mismo que juntó a heterogéneas tendencias ciudadanas, cansadas de un modelo partidista desacreditado por los pocos logros sociales y continuos errores económicos. Rafael Correa ha liderado el movimiento PAIS, planteando en su plan de gobierno un proyecto político, que posicionó como eje discursivo el bien común, conjuntamente con una propuesta utópica de Estado, interpeladora de un modelo de desarrollo capitalista neoliberal, contraponiendo como propuesta política y electoral al denominado "buen vivir" (Larrea, 2011).

El movimiento PAIS propone la retoma o renacimiento de una sociedad civil vinculada al ciudadano, una Revolución Ciudadana. Esta

13 Las alianzas con líderes de pueblos y nacionalidades indígenas tienen alcances simbólicos, su impacto político no podría ser medido por votos, debería ser medido por los acuerdos y los potenciales espacios activos de participación y diálogo que caracterizarían a un modelo de hacer política (Trujillo, 2016).

14 Campo, concepto retomado de Bourdieu (1991) quien lo señala como el espacio donde se juega la política. 
última década ha logrado aglutinar diversas tendencias y facciones políticas que se han legitimado sobre continuos triunfos en procesos electorales y sobre todo alrededor de la figura carismática de Correa, un político que ha liderado la mayor transformación y cambio social ${ }^{15}$ en Ecuador, conjuntamente con la mayor politización de la sociedad ecuatoriana en décadas. La forma confrontativa de actuar en la política por parte de Correa ha contribuido a politizar la sociedad ecuatoriana, generando una compleja polarización de la misma, provocando esencialismos y la pérdida sistemática del diálogo entre los diversos actores políticos (Trujillo, 2016).

Posterior al contundente triunfo electoral del 2013, para el movimiento PAIS ganar las cercanas elecciones de gobiernos seccionales del 2014 fueron estratégicas, con el objetivo de dividir y debilitar aún más a la oposición y consolidar una hegemonía política nacional, regional y local. Sin embargo, en ese proceso, los resultados electorales se convirtieron en un revés no programado. A pesar de mantener una alta votación a nivel nacional, que ratificaba al movimiento PAIS como la primera fuerza política del Ecuador, había perdido las principales capitales provinciales, iniciando un inestable periodo y desinfle para la Revolución Ciudadana.

Rafael Correa ha sido el político que mayor capital político y simbólico ha acumulado en estos últimos diez años. Su gestión ha sido la más efectiva en la reducción de la pobreza, la inequidad y las brechas sociales. Sin embargo, a pesar de una creciente bonanza económica que ha consolidado una clase media ecuatoriana, existe una polarización social que ha provocado enfrentamientos sociales y múltiples protestas. Las futuras elecciones presidenciales y de Asambleístas en 2017 serán la prueba político-electoral más importante para consolidar o no una nueva etapa de la Revolución Ciudadana. Eso sólo lo sabremos cuando los votos se cuenten y se den los resultados de un nuevo proceso electoral en el Ecuador contemporáneo.

15 https://goo.gl/clySqp (Consultado, 03-09-2016). 


\section{Bibliografía}

Alcántara, M. (2013). Calidad de los políticos y calidad de la política. México: Biblioteca Jurídica-UNAM

Alcántara, M. (2012). El oficio del Político. Madrid: Tecnos.

Arenas, N. (2012). "Post-Neoliberalismo en América Latina: en busca del paradigma perdido". En Revista Aportes para la Integración Latinoamericana. Año XVIII, No 27, diciembre, pp. 22-49.

Balbi, F. A. (2007). La dudosa magia del carisma. Explicaciones totalizadoras y perspectiva etnográfica en los estudios sobre el peronismo. Buenos Aires.

Bourdieu, P. (1991). Language \& Simbolic Power. USA: Harvard University Press.

De la Torre, C. (2012). El tecno populismo de Rafael Correa ¿Es compatible el carisma con la tecnocracia? Lexington: University of Kentucky.

Freidenberg, F. (2012). "Ecuador 2011: Revolución Ciudadana, estabilidad presidencial y personalismo político”. En Revista de Ciencia Política. Instituto de Iberoamérica. Universidad de Salamanca. / Volumen 32 / $\mathrm{N}^{\mathrm{o}} 1 / 129-150$.

Larrea, A. M. (2011). Modo de desarrollo, organización territorial y cambio constituyente en el Ecuador. Quito: SENPLADES.

Lipset, S. M. y S. Rokkan. (2001). “Cleavage Structures, Party Systems, and Voter Alignments". En Peter Mair (ed.) The West European Party System. Oxford: Oxford University Press.

Muñoz Jaramillo, F. (2009). La coyuntura de cambio en Ecuador. Estado y régimen político y constitucional. Paris: IRG. 
Montúfar, C. (2012). La dictadura plebiscitaria: Neoconstitucionalismo y construcción de un nuevo Régimen Político. El Ecuador a inicios del Siglo XXI. Quito: Universidad Simón Bolívar.

Ospina, P. (2011). “Ecuador: ¿intento de golpe o motín policial?”. En Revista Nueva Sociedad. N²31, enero-febrero.

Pachano, S. (2007). La trama de Penélope. Quito: Flacso-Ágora Democrática-International Idea-Inmd.

Polga, J. (2013). Overcoming the Regional Cleavage? The (Unprecedented) Territorial Nationalization of Alianza País. Quito: FLACSO.

Ramos, M y A. Páez. (2010). El magnicidio perfecto: Análisis de la crisis del 30 de septiembre del 2010. Quito: Centro Andino de Estudios Estratégicos CENAE.

Ramírez, F. (2011). "Desencuentros, convergencias, polarización (y viceversa). El gobierno ecuatoriano y los movimientos sociales". Revista Nueva Sociedad. Nº 227.

Ramírez, F y F. Pagliorone. (2014). En Martin-Carrillo y De Gori. Disputas por el Poder. Coyunturas Electorales en América Latina. Quito: IAEN.

Trujillo, P. (2013) ¿Cómo se ganó las elecciones en el 2013? Etnografía a la operación política de la revolución ciudadana. Monografía. Quito: FLACSO.

Trujillo, P. (2016). Los operadores políticos de la Revolución Ciudadana. Tesis doctoral. Quito: FLACSO.

Unda, M. (2011). "Una vez más sobre la relación entre el gobierno de correa y los movimientos sociales". Revista virtual. Línea de Fuego. 
Žižek, S. (1998). Estudios Culturales. Reflexiones sobre el multiculturalismo. Buenos Aires: Paidós, pp. 137-188.

\section{Otras fuentes:}

Consejo Nacional Electoral (CNE), www.cne.gob.ec

CEDATOS, www.cedatos.com.ec

Diario El Universo. www.eluniverso.com

MOVIMIENTO PAIS, PLAN DE GOBIERNO 2009-2013, 2013-2017. www.movimientoalianzapais.com.ec

Opinión Pública Ecuador, www.opinionpublica.ec

Secretaria Nacional de Planificación y Desarrollo (SENPLADES), www. planificacion.gob.ec 